\title{
Discussion on the Construction of New Countryside in China: A Case Study of Hebei Province
}

\author{
Pengcheng PAN ${ }^{1, a}$, Shiyao WANG ${ }^{1, b}$, Jinxin $Z U^{1, c}$ and Zhiyu $\mathrm{NI}^{1, \mathrm{~d}}$ \\ ${ }^{1}$ Department of Civil Engineering, School of Civil Engineering and Mechanics, Yanshan University, \\ Qinhuangdao, Hebei, 066004, China \\ appc@ysu.edu.cn, b871240341@qq.com, ${ }^{c} 535244347 @ q q . c o m,{ }^{d}$ nizhiyu@ysu.edu.cn
}

Keywords: The Construction of New Countryside, Problems, Countermeasures, Hebei Province Abstract. Based on the investigation on Construction of New Countryside in Hebei Province, the current situations about Construction of New Countryside in the Province were analyzed. The problems of Construction of New Countryside in the Province were mainly as follows: officials at the grass-roots level only paid attention to "face" and ignored the "essence"; planning was separated from reality; planning could not been effectively implemented, the degree of participation of famers was low; the source of financing was single. On the basis of analysis, The countermeasures were put forward: pay more attention to "essence" than "face"; scientific and rational planning; usage of rural property management services, broadening the financing channels.

\section{Introduction}

The construction of New Countryside has important significance to the socialist construction of our country. Without the stability and overall progress of the rural areas, there can be no stability and overall progress of the whole society. Hebei province is a large agricultural province with abundant resources and large population. It is an objective demand to deal with the challenge of the socialist market economic development and the urgent task of building the harmonious construction of New Countryside in Hebei. Based on the present situation of the New Countryside in Hebei Province, the problems existing in the construction of New Countryside were discussed in this paper and the countermeasures to solve the problems were put forward. The research has practical significance for the Construction of New Countryside in Hebei province and even for others provinces.

\section{Current Situation of the Construction of New Countryside in Hebei Province}

In Hebei Province, great progress has been achieved during the last few years in Construction of New Countryside, Among the first batch of 1000 exemplary villages started in 2009, nearly 80\% of them completed the construction and transformation tasks. In 2010, other 2000 exemplary villages all started building task, $80 \%$ of them has obvious progress. As of 2015, the infrastructure in Hebei was significantly strengthened. Water supply, roads, gas stations, electricity, telecommunications were, as the focus of infrastructure construction in countryside, accelerated. Achievement were as follows: basic on the asphalt or concrete road, every village has the coach services; Based on the transformation of rural power grids, household electrical supply was basically realized; in village which has more than 50 households access to television; the problem of safe drinking water of 366 million rural population in province was newly solved; 16 million households has the biogas newly and a total number of more than 300 million households have been completed, which was ranks fourth in the whole country ${ }^{[1]}$.

The practice proved that, the promotion of the Construction of New Countryside in Hebei Province conforms to the requirements of the scientific development concept, the social development of economy and the transformation of the developmental mode, It is an effective combination of urban and rural development. It is effective to improve the production and living conditions of farmers, promote rural land saving and intensive use, expand consumption and stimulating investment. 


\section{The Existing Problems of the Construction of New Countryside in Hebei}

Despite the great achievements in Hebei Province, however, from our survey, there are still some unsatisfactory factors, specifically as follows:

\subsection{Only Focusing on "face" and Ignoring the "essence"}

Some grass-roots officials mistakenly think that the new buildings, wide avenues, big square, sculpture and so on "face" projects are important. They shift their attention to the image of the packaging, make the Construction of New Countryside became the "Face projects" and "achievement projects". Gorgeous memorial archways and stylish village committees will be built in the construction of New Countryside repeatedly, which does not match with the local cultural characteristics and economic development level. These buildings, although expensive, were no substantial effect for the improvement of the living standards of farmers. "Face projects" had become a speculation means of local cadres to cope with the higher level government's check and improve their own performance.

\subsection{The Lack of Effective Planning}

Because of a large number of countryside in Hebei, the tight schedule and the heavy task, the planning of Construction of New Countryside often have no sufficient research, which leads to the inappropriate decision. The planning had not agree with the actual situation of the countryside. These do not meet the wishes of the village planning content. The rate of use(Reformed house) was so low after the implementation in some project. Taking the transformation of residential areas as an example, some countryside officer ignored the basic starting point of the transformation of the houses. The focus was the residential house whose quality was poor. In the process of the transformation of the dwelling house, it should keep that the characteristics of the village's houses, should meet the basic needs of the villagers' production and life, and respect the villagers' production and living habits. For the village's visual appearance, one-sided seek for the unity and the same face of a thousand villages, ignoring the farmers' needs and economic affordability were not feasible. It was not reasonable to get the villagers go upstairs uniformly ${ }^{[2]}$. Some unified two-floors villa style residential had been built somewhere in Qinhuangdao City and Zhangjiakou city. Due to the local economic conditions, it is not in line with the local living habits, almost no farmer family moved into the building after completion.

\subsection{The Lack of effective implementation of Planning}

In the specific implementation process of the planning program, there was phenomenon that lack of effective implementation of the planning, due to the lack of technical guidance, large capital gap and the high transformation difficulty. On the other hand, the transformation and upgrading of countryside were basic and social welfare projects, often using government investment mainly. Some government policy makers hope to accomplish something in his/her term, so he/she often neglect to long-term benefits of transform and upgrade project and the actual demands of the villagers were not respected. one-sided pursuit of sensationalism and short-term benefits were popular. To accomplish immediate interests as soon as possible, and strive to short term benefits, the selective planning were implemented by local government. Above two items were the reasons leading to the reasonable planning were often not effectively implemented.

\subsection{The Lack of Public Participation}

The basic principle of rural reconstruction and upgrading plan was people-oriented. Measures should be Adjusted to local conditions. Whether the plan fully respect the wishes of the villagers, to meet the needs of the villagers was an important evaluation criteria for the merits of the planning program. The program must vote by the villagers' congress. But in the planning and implementation process, we found that villagers' participation has become one of the prominent problems restricting the transformation and upgrading of countryside ${ }^{[3]}$. A reason of low participation was that most of the villagers' culture level is not high, lack of overall view, only to see the immediate benefits, it is difficult for them to see the long-term benefits of the construction of New Countryside. The villagers in the face of personal and collective interests can not make the right choice. 


\subsection{The Lack of Financial Support}

The construction of New Countryside was a continuous, huge project, to complete the projects, have sufficient funds were necessary. In the actual construction process, the funding was relatively limited. Most of funding have to rely on the government financial investment. Such as Zhangjiakou and Chengde City, the government funding accounted for $86 \%$ and $74 \%{ }^{[4]}$. At present, in Hebei Province, faced with economic restructuring, most counties and cities had more financial difficulties to enhance the transformation of the rural landscape, government funding cannot meet the needs at the grass-roots level in countryside, even some special funding only stay in the book. Some funding were used to other things such as built a Commercial house. the lack of effective supervision to government funding was also a serious problem.

\section{Countermeasures for the Construction of New Countryside}

\subsection{Attach Importance to "face" and Value the "essence" More}

Do a good job in the construction of New Countryside, we must combine the village of the actual situation, adjust measures to local conditions, steadfast, step-by-step, one or two "face project" will not be able to succeed in a sustained way. New roads, parks, squares and green spaces take countryside on an altogether new aspect and improve the rural functional facilities, but also bring a great convenience to the villagers. But such the "essence" project as sewage pipe network, was closed to the villagers' daily life. The construction of New Countryside in order to achieve the expected results, the village needs to be classified according to the level of economic development, and formulate the development of different levels of standards. On the one hand, we should consider such "face" as streets and squares in order to improve the sense of honor of the villagers, on the other hand, spend more time to solve " essence " problems about villagers' living kitchen, drainage, garbage of the villagers, enhance the sense of ownership of the villagers. Add more honor to new rural construction by real "essence ".

\subsection{Scientific Planning and Fast Implementation}

Hebei Province is a province with vast area, complex and diverse topography. There are 6 ethnic autonomous districts in the province. The diversity and distributions has led to the current problems in rural areas, includes both common problems and special issues that need to be treated differently. Planners need to formulate different countermeasure with the characteristics of different districts.

Take the national culture as an example. In more than 50000 villages in Hebei Province, there are a large number of ethnic minority villages, some of which have their own local culture. In these villages, the unique architectural style and traditional style has become beautiful scenery. There are also a number of villages in the higher level of urbanization, the appearance of village was similar to the city. In the process of planning and construction of New Countryside, we cannot establish a village as typical, forcing other villages to it on par. The characteristics should be combined with the village, the implementation of " One Brand for Each Village ".

\subsection{Develop Rural Property Management}

The property management was traditionally used in population concentration district, such as cities, and the property management was a community service institution that was well known to people. But in some country or some villages, population was relatively concentrated and economic condition was good, we can introduce the property management to these villages, combine construction with administration and form a long-term mechanism to enhance the transformation of the rural landscape. We assume that the rural property is a unit of the village or town, which is responsible for the management of the operation and maintenance of rural life garbage and related safety, production and living facilities.

From the survey in winter of 2015, The farmers' property management needs in Hebei Province can generally include: Housing maintenance, sanitation cleaning, security, greening and beautifying, farm machinery repair, collective heating, agricultural products storage etc. We found that the top three needs of the villagers are security, cleaning, agricultural storage, which can provide practical guidance for the Construction of New Countryside in Hebei. 


\subsection{Broaden the Financing Channels}

Lack of funding has become the biggest constraint in the Construction of New Countryside. For a long time, due to the shortage of governments' financial investment in countryside, especially the later-stage investment, the construction of rural infrastructure was lagging behind, the infrastructure was seriously aging. The construction of New Countryside has become a gust of wind and it can not give the villagers the lives of long-term convenience. Therefore, the government should determined to adjust the structure of fiscal funds, increase financial support for the continued investment in countryside.

"Public-private Partnership(PPP)" is a hot topic during the "two sessions" in 2015."PPP " is a kind of cooperation mode between public government departments and private enterprises. It refers to the government and private organizations, in order to cooperate in the construction of infrastructure projects and reach an agreement ${ }^{[5]}$.In simple terms, the Construction of New Countryside, the government and the successful third party companies signed a franchise contract, the third part of the company responsible for the financing, construction and management of part of the project. "PPP financing model" to make the private capital more involved in the actual project, in the early construction of the government to reduce the burden of investment and the risk of the premise, improve the service quality of infrastructure construction. Rural reconstruction is unavoidable in the process of private enterprise financial and technical support, the PPP financing mode in the countryside has great significance to the promotion.

\section{Conclusions}

The Construction of New Countryside is a complex systems engineering. The "face" and "essence" problem, scientific planning and implementation, the usage of rural property management, diversification of financing channels, were four key points. If we can follow the economic development law, make reasonable decision, and actively explore the problems and solutions, the Construction of New Countryside will succeed in the near future.

\section{Acknowledgements}

This work was supported by the Key Projects of Social Sciences Research, City of Qinhuangdao(Grant No.201506035), Yanshan university Training Program of Innovation and Entrepreneurship for Undergraduates.

\section{References}

[1] Information on Http://he.people.com.cn/n/2015/0127/c200202 23704258.Html.(In Chinese)

[2] Li Gang. Chinese Township and Village Enterprises. Vol. 117 (2011), p. 4-5. (In Chinese)

[3] Yang Chunjuan. Journal of Hebei Youth Administrative Cadre Institute. Vol. 32 (2007) , p. 17-19. (In Chinese)

[4] Feng Shi Gang. Journal of Hebei Software Vocational and Technical College. Vol. 43 (2013),p. 38. (In Chinese)

[5] Wu shixun. Journal of Hebei Science and technology Normal University (SOCIAL SCIENCE EDITION). Vol. 87 (2015), p.21. (In Chinese) 